\title{
MEIS1 promotes expression of stem cell markers in esophageal squamous cell carcinoma
}

\author{
Selma Zargari ${ }^{1 \dagger}$, Shabnam Negahban Khameneh ${ }^{2 \dagger}$, Abolfazl Rad ${ }^{3}$ and Mohammad Mahdi Forghanifard ${ }^{2^{*}}$ (D)
}

\begin{abstract}
Background: MEIS1 (Myeloid ecotropic viral integration site 1) as a homeobox (HOX) transcription factor plays regulatory roles in a variety of cellular processes including development, differentiation, survival, apoptosis and hematopoiesis, as well as stem cell regulation. Few studies have established pluripotency and self-renewal regulatory roles for MEIS1 in human esophageal squamous cell carcinoma (ESCC), and our aim in this study was to evaluate the functional correlation between MEIS1 and the stemness markers in ESCC patients and cell line KYSE-30.

Methods: Expression pattern of MEIS1 and SALL4 gene expression was analyzed in different pathological features of ESCC patients. shRNA in retroviral vector was used for constantly silencing of MEIS1 mRNA in ESCC line (KYSE-30). Knockdown of MEIS1 gene and the expression pattern of selected stemness markers including SALL4, OCT4, BMI-1, HIWI, NANOG, PLK1, and KLF4 were evaluated using real-time PCR.

Results: Significant correlations were observed between MEIS1 and stemness marker SALL4 in different early pathological features of ESCC including non-invaded tumors, and the tumors with primary stages of progression. Retroviral knockdown of MEIS1 in KYSE-30 cells caused a noteworthy underexpression of both MEIS1 and major involved markers in stemness state of the cells including SALL4, OCT4, BMI-1, HIWI and KLF4.

Conclusions: The results highlight the important potential role of MEIS1 in modulating stemness properties of ESCCs and cells KYSE-30. These findings may confirm the linkage between MEIS1 and self-renewal capacity in ESCC and support probable oncogenic role for MEIS1 in the disease.
\end{abstract}

Keywords: Self-renewal, ESCC, KYSE-30, MEIS1, Stemness markers

\section{Background}

Human esophageal cancer is the sixth leading cause of cancer-related mortality worldwide [1]. Esophageal squamous cell carcinoma (ESCC) is one of the main subtypes of esophageal cancer. In spite of using modern surgical techniques combined with adjuvant treatment, the

\footnotetext{
* Correspondence: forghanifard@gmail.com; Forghanifard@damghaniau.ac.ir 'Selma Zargari and Shabnam Negahban Khameneh contributed equally to this work.

2Department of Biology, Damghan branch, Islamic Azad University, P.O.Box: 3671639998, Cheshmeh-Ali Boulevard, Sa'dei Square, Damghan, Islamic Republic of Iran

Full list of author information is available at the end of the article
}

overall 5-year survival rate of the patients still remains nearly $15-20 \%$ [2].

Increasing evidence demonstrate that tumors are maintained by cancer stem-like cells (CSCs). CSCs are a small population of cells with self-renewal capacity in most tumors which can promote tumor proliferation, metastasis, and drug resistance. CSCs are also considered as a source of cancer recurrence even after conventional therapies [3]. The two most essential properties of stem cells are pluripotency and self-renewal. Pluripotency is the capacity of stem cells to produce any cell type with specialized properties whereas the ability of

(c) The Author(s). 2020 Open Access This article is licensed under a Creative Commons Attribution 4.0 International License, which permits use, sharing, adaptation, distribution and reproduction in any medium or format, as long as you give appropriate credit to the original author(s) and the source, provide a link to the Creative Commons licence, and indicate if changes were made. The images or other third party material in this article are included in the article's Creative Commons licence, unless indicated otherwise in a credit line to the material. If material is not included in the article's Creative Commons licence and your intended use is not permitted by statutory regulation or exceeds the permitted use, you will need to obtain permission directly from the copyright holder. To view a copy of this licence, visit http://creativecommons.org/licenses/by/4.0/ The Creative Commons Public Domain Dedication waiver (http://creativecommons.org/publicdomain/zero/1.0/) applies to the data made available in this article, unless otherwise stated in a credit line to the data. 
self-renewal is described as the proliferation capacity of the cells for prolonged periods of time and regenerating the tissue [4].

Homeobox $(H O X)$ genes, a large and essential family of developmental regulators, are vital for growth, differentiation and development of numerous organ systems [5, 6]. Myeloid ecotropic insertion site 1 (MEIS1) is a developmentally conserved member of 3-amino-acid loop extension (TALE) family which can interact with HOX proteins as a cofactor [7]. HOX and MEIS1 are involved in different biological processes such as chromatin remodeling, cell cycle control, apoptosis and differentiation, as well as transcription adjustment of self-renewal genes [8-10]. Deregulated MEIS1 mRNA and protein expression can lead to tumorigenesis in a number of tumor types such as acute myeloid leukemia [11], lung adenocarcinoma tumors [12], neuroblastomas [13], ovarian carcinomas [14] and ESCC [15]. Recent evidence suggested a tight association between MEIS1 and selfrenewal signature in hematopoietic and neural stem cells [16]. Moreover, the correlation between MEIS1 and CSC marker SOX2 has been shown in ESCC predicting cancer stemness properties for MEIS1 in the disease [15]. Several CSCs markers are proposed as ESCC CSC markers such as OCT4, BMI-1, SALL4, HIWI and KLF4. Since these markers are frequently up-regulated in different malignancies, a regulatory role in maintenance of pluripotency and self-renewal has been suggested for these genes [17-22].

Since, phenotypic and functional properties of CSCs are regulated through a variety of extrinsic signaling pathways and intrinsic self-renewal factors [23-25], there is an urgent need to explore its details to provide specific targeted therapies for various cancers including ESCC. In the present study the correlation between expression pattern of MEIS1 and different stem cell markers including SALL4, OCT4, BMI-1, KLF4 and HIWI was investigated in ESCC patients and cell line to evaluate the potential correlation between MEIS1 and stemness state of the cells.

\section{Methods}

\section{Study population}

The clinicopathological features of 50 ESCC patients and related gene expression pattern of MEIS1 and SALL4 in the tumors compared to the adjacent tumor free tissues were used in this study. As previously described [15, 26], patients selection was restricted to a specific conditions, and both informed consent of patients to be involved in the study and approval of the ethic committee of Mashhad University of Medical Sciences, Mashhad, Iran, were recorded.

\section{Cell lines and culture condition}

Human ESCC (KYSE-30) and embryonic kidney (HEK293T) cell lines were purchased from the Pasteur Institute Cell Bank of Iran (http://en.pasteur.ac.ir/) and grown in RPMI 1640 medium (Biosera) and Dulbecco's modified Eagle's medium (DMEM; Biosera), respectively. Both culture media were supplemented with $10 \%$ heatinactivated fetal bovine serum (FBS; Gibco, USA), 100 $\mathrm{U} / \mathrm{ml}$, and $100 \mu \mathrm{g} / \mathrm{ml}$ penicillin-streptomycin (Gibco, USA) and cultured at a humidified atmosphere 37 C with 5\% CO2. The KYSE-30 cell line was last successfully authenticated by short tandem repeat profiling at the Pasteur Institute Cell Bank of Iran.

\section{MEIS1 gene expression knockdown}

Based on principles of shRNA design and the human MEIS1 structure (GenBank reference sequence: NM 002398.3) [27], the lentivirus-based pLKO.1-puro plasmid (Cat. No. SHC003) was constructed by SigmaAldrich (St. Louis, MO). The pLKO.1-puro plasmid DNA was labeled with a cytomegalovirus (CMV) promoter driving expression of the green fluorescent protein (GFP) gene. Lentivirus production was followed by transfecting HEK293T cells according to the standard calcium phosphate method with pLKO.1-MEIS1, together with the psPAX2 and the pMD2.G as packaging vectors [28] (plasmids 12,260 and 12,259, respectively, Cambridge, MA). Viral supernatant was harvested 24 and $48 \mathrm{~h}$ after transfection, filtered through a $0.45-\mu \mathrm{m}$ filter (Orange, Belgium). Then, the virus was recovered after ultracentrifugation $(40-\mathrm{mL}$ culture medium per 50 $\mathrm{mL}$ Beckman tube, ultracentrifugation $70,000 \times \mathrm{g}, 4^{\circ} \mathrm{C}$ for $2 \mathrm{~h}$ ) and resuspended in fresh medium, and used to transduce KYSE-30 cells which were cultured at a density of $0.5-1 \times 10^{\wedge} 6$ cells in 6 -well plate the previous day. Cells were continuously cultured for 4 to 5 days followed by selection with puromycin (Invitrogen Corporation, Carlsbad, CA). The transduced KYSE-30 cells with recombinant lentiviral particles of GFP (control) and GFPshMEIS1 were assayed using inverted fluorescence microscopy.

\section{RNA extraction, cDNA synthesis, comparative real time PCR}

Tripure reagent (Roche, Nutley, NJ) was used to extract RNA from GFP and GFP-shMESI1 transduced ESCC cell line, as recommended by the manufacturer. Subsequently DNase I (Thermo Fisher Scientific, Waltham, MA) treatment was performed for preventing DNA contamination. Total RNA was used as a template for the synthesis of cDNA using the oligo-dT method (Fermentas, Lithuania). Following cDNA synthesis, qRT-PCR was used to assess MEIS1 mRNA knockdown. Furthermore, relative comparative changes of BMI1 (GenBank 
reference sequence: NM_005180.9), SALL4 (GenBank reference sequence: NM_001318031.2), KLF4 (GenBank reference sequence: NM_001314052.2), OCT4 (GenBank reference sequence: NM_001173531.2), NANOG (GenBank reference sequence: NM_024865.4), PLK1 (GenBank reference sequence: NM_005030.6), and HIWI (GenBank reference sequence: NM_001190971.2) mRNA expressions were assessed in MEIS1 silenced compared to GFP control cells using a relative comparative realtime PCR using gene-specific primer sets shown in Table 1. GAPDH housekeeping gene was used as a normalizer and 2- $\Delta \Delta \mathrm{Ct}$ method was used to measure fold changes of gene expression [29]. Briefly, PCR was performed in a total volume of $20 \mu \mathrm{L}$ in $1 \times$ SYBR Green Real Time PCR Master Mix (AMPLIQON, Denmark) containing $0.5 \mu \mathrm{M}$ of each primer and was done on a LightCycler 96 Real-Time PCR System thermocycler (Roche, Germany). While the $\log 2$ fold changes in mRNA expression more than 2 , and less than -2 folds were considered as overexpression and underexpression, respectively, the range in between was regarded as normal expression.

\section{Statistical analysis}

The SPSS 19.9 statistical package (SPSS, Chicago, IL, USA) was applied for statistical data analysis. $P$ value < 0.05 was regarded as statistically significant. We used the $x^{2}$ or Fisher exact tests and Pearson's correlation to evaluate the association between gene expressions.

\section{Results}

\section{MEIS1 gene expression is correlated with SALL4 in ESCC} patients

Gene expression pattern of MEIS1 and SALL4 in 50 ESCC patients was used here to analyze correlation between these genes in different clinicopathological features of the patients. The clinicopathological characteristics of recruited patients are presented previously [15]. Based on statistical analysis, a significant correlation was observed between MEIS1 and SALL4 gene expression in ESCCs $(P=0.022$, correlation coefficient: 0.322). The expression pattern of MEIS1 and SALL4 was synced to each other in more than half of the patients (52\%, 26 of 50 samples). As described in Table 2, overexpression of both genes was observed in nine patients and concomitant unchanged/underexpression of the genes was detected in 17 tumor samples. Correlation between the genes is depicted in Fig. 1 as regression plot.

Interestingly, significant correlation was detected between MEIS1 and SALL4 in non-invaded tumors into the adventitia (T1/T2, $P=0.017$, correlation coefficient: 0.699 ) but not in invaded tumors (T3/T4, $P=0.114$, correlation coefficient: 0.257 ). In addition, MEIS1 was significantly correlated with SALL4 in tumors without metastasis to the lymph node $(P=0.023$, correlation coefficient: 0.427$)$ in contrast with lymph node metastasized tumors $(P=0.453$, correlation coefficient: 0.169$)$. And finally, a noteworthy correlation between the genes was found in early stages of tumor progression (stage I/ II, $P=0.030$, correlation coefficient: 0.390 ), while in advanced stages of the disease (stages III/IV) the correlation was not significant $(P=0.439$, correlation coefficient: 0.189). The expression pattern of MEIS1 and SALL4 in different pathological states of the ESCCs is summarized in Table 3.

\section{Lentivirus-mediated shRNA efficiently knocks down expression of MEIS1}

To deliver shRNA into the esophageal cancer cell line KYSE30, we used a lentiviral-based vector that expressed MEIS1 shRNA. KYSE30 cells were transduced with MEIS1 expressing viral particles and selected by puromycin $48 \mathrm{~h}$ after transduction. Ten days post transduction; cells were analyzed for MEIS1 expression using real-time PCR. Compared with the negative control group the level of MEIS1 (mRNA) expression in the infected cells was sharply reduced (log2 fold change: 5.6). These data demonstrated that the expression of MEIS1 gene is efficiently downregulated in transduced cells KYSE-30.

Table 1 Primer sequences used for qRT-PCR in this study

\begin{tabular}{|c|c|c|c|}
\hline Gene & Forward primer & Reverse primer & Amplicon size \\
\hline MEIS1 & ATGACACGGCATCTACTCGTTC & TGTCCAAGCCATCACCTTGCT & 105 \\
\hline BMI1 & CGTGTATTGTTCGTTACCTGGAGAC & CATTGGCAGCATCAGCAGAAGG & 204 \\
\hline SALL4 & CCAGGGAATGACGAGGTGG & GAACTCCGCACAGCATTTCTC & 96 \\
\hline KLF4 & TCTTCTCTTCGTTGACTTTG & GCCAGCGGTTATTCGG & 210 \\
\hline OCT4 & GAACATGTGTAAGCTGCGGCC & CCCTTCTGGCGCCGGTTAC & 148 \\
\hline HIWI & ATGATTGAAGTGGATGACAGAACTG & TACTTGACAACAGACAGACAACTAT & 97 \\
\hline GAPDH & GGAAGGTGAAGGTCGGAGTCA & GTCATTGATGGCAACAATATCCACT & 101 \\
\hline NANOG & GGCAATGGTGTGACGCAGAAGGC & GCTCCAGGTTGAATTGTTCCAGGTC & 137 \\
\hline PLK1 & ATAGAGCGTGACGGCACTGAGT & TGCTCGCTCATGTAATTGCG & 107 \\
\hline
\end{tabular}


Table 2 Concomitant expression of MEIS1 and SALL4 in ESCCS $(P=0.022)$

\begin{tabular}{lllll}
\hline & & \multicolumn{2}{l}{ SALL4 expression } & Total \\
\cline { 3 - 4 } & & Normal/under & Overexpression & \\
\hline MEIS1 & Normal/under & 17 & 22 & 39 \\
expression & Over & 2 & 9 & 11 \\
Total & 19 & 31 & 50 \\
\hline
\end{tabular}

\section{Down-regulated expression of MEIS1 by shRNA decreased} the expression of stemness genes

The expression of cancer stem cell markers was assessed in MEIS1 silenced cell line compared to control. Downregulation of MEIS1 led to a significant decrease in the levels of the most important stem cell markers BMI1, SALL4, OCT4 and KLF4 mRNA expression (log2 fold change: $-14.28,-5,-7.14$ and -5.26 fold, respectively) in KYSE30 cells. Furthermore, the level of HIWI mRNA expression was significantly reduced about -14.28 in MEIS1 silenced cells in comparison with control. The levels of gene expression are presented in Fig. 2 as box plot. These data clearly showed the significant decrease in expression of the majority of selected stemness genes in KYSE-30 cells after MEIS1 silencing. No changes were observed in mRNA expression of NANOG and PLK1 following silencing of MEIS1 in KYSE-30 cells.

\section{Discussion}

ESCC is one of the invasive malignancies of gastrointestinal tract with considerable mortality and morbidity rate [30]. Therefore, understanding the molecular mechanisms behind the esophageal tumorigenesis is crucial for achieving the best diagnostic and therapeutic approaches. Different cancer propagation models have been described and CSC model is an interesting one. However, evaluating the stemness behavior of ESCC has not been widely studied.

The present study demonstrated the impact of MEIS1 on expression of stem cell markers in ESCC and found that mRNA expression of major stem cell markers including SALL4, OCT4, BMI-1, HIWI and KLF4 was significantly decreased in MEIS1 silenced cells compared to control. Furthermore, the expression patterns of MEIS1 and stemness marker SALL4 were significantly associated to each other depending on different pathological features of the patients, specifically in early stages of tumor progression.

The correlation between MEIS1 and involved genes in self-renewal and pluripotency of different CSCs has been discussed in few studies. It has been revealed that meis $1^{-1-}$ mice die because of abnormalities in hematopoiesis and vascularization due to lack of hematopoetic stem cell (HSC) niches in the embryos. These

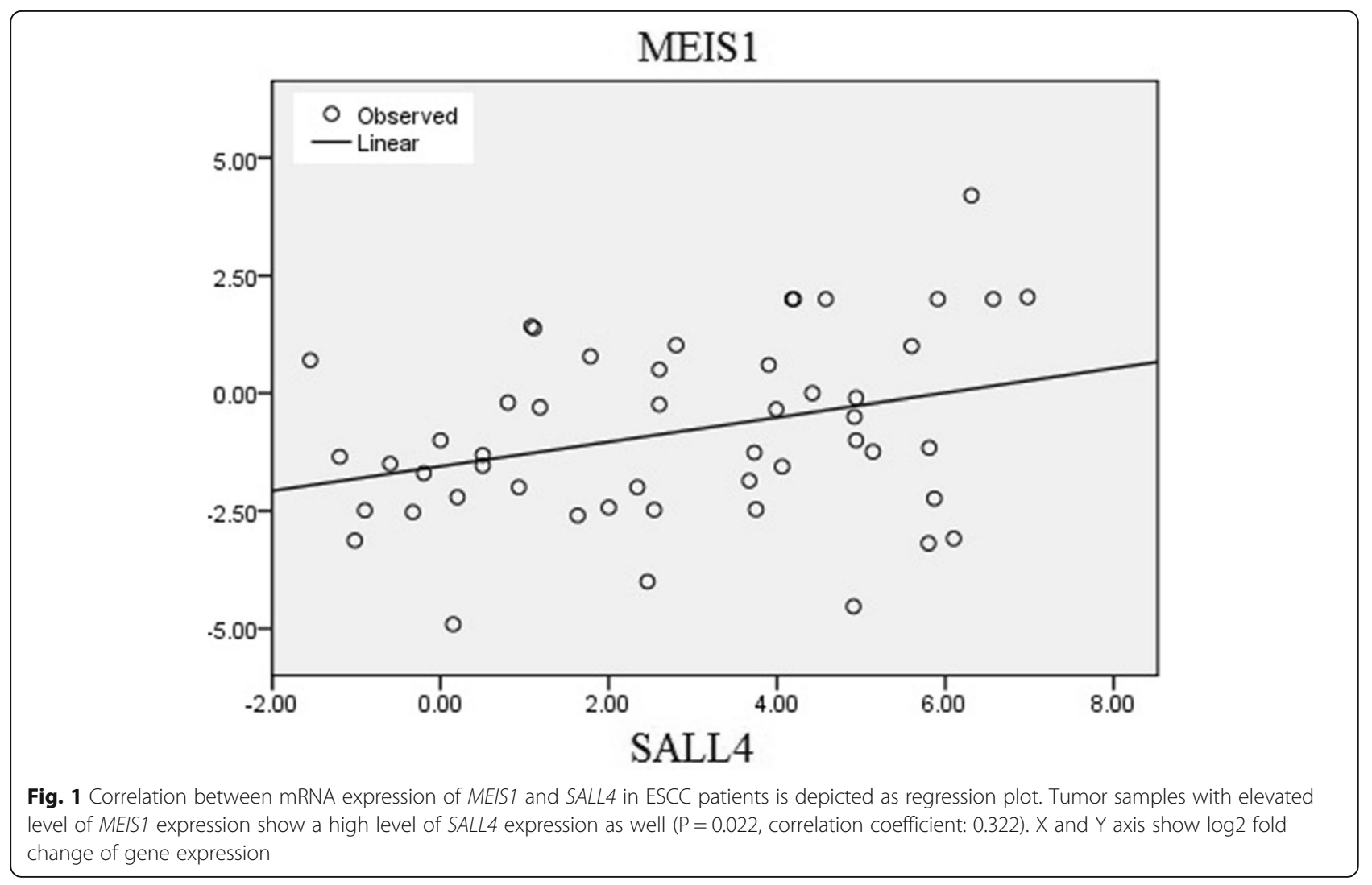


Table 3 The expression pattern of MEIS1 and SALL4 in different pathological states of the ESCCS

\begin{tabular}{|c|c|c|c|c|c|c|}
\hline & & \multicolumn{2}{|c|}{ MEIS1 expression } & \multicolumn{2}{|c|}{ SALL4 expression } & \multirow[t]{2}{*}{$p$-value } \\
\hline & & Normal/under & $\overline{\text { Over }}$ & Normal/under & $\overline{\text { Over }}$ & \\
\hline \multirow[t]{2}{*}{ Sex } & Male & 18 & 6 & 9 & 15 & \multirow[t]{2}{*}{$P=0.521$} \\
\hline & Female & 21 & 5 & 10 & 16 & \\
\hline \multirow[t]{2}{*}{ Lymph node metastasis } & No metastasis & 20 & 8 & 13 & 15 & \multirow[t]{2}{*}{$P=0.023^{*}$} \\
\hline & Node metastasis & 19 & 3 & 6 & 16 & \\
\hline \multirow[t]{2}{*}{ Depth of invasion } & $\mathrm{T} 1,2$ & 8 & 3 & 1 & 10 & \multirow[t]{2}{*}{$P=0.017^{*}$} \\
\hline & $\mathrm{T} 3,4$ & 31 & 8 & 18 & 21 & \\
\hline \multirow[t]{2}{*}{ Stage of progression } & Stage $|/| \mid$ & 23 & 8 & 12 & 19 & \multirow[t]{2}{*}{$P=0.030^{*}$} \\
\hline & Stage III/IV & 16 & 3 & 7 & 12 & \\
\hline \multirow[t]{3}{*}{ Grade of differentiation } & P.D** & 5 & 1 & 4 & 2 & \multirow[t]{3}{*}{$P=0.231$} \\
\hline & M.D & 27 & 6 & 9 & 24 & \\
\hline & W.D & 7 & 4 & 6 & 5 & \\
\hline \multirow[t]{3}{*}{ Location } & Lower & 18 & 4 & 9 & 13 & \multirow[t]{3}{*}{$P=0.327$} \\
\hline & Middle & 20 & 6 & 9 & 17 & \\
\hline & Upper & 1 & 1 & 1 & 1 & \\
\hline
\end{tabular}

*Asterisk show statistical significance

**P. D Poorly Differentiated, M. D Moderatly Differentiated, W. D Well Differentiated

findings highlighted the important role of MEIS1 in HSC regulation [31, 32]. MEIS1 has a critical role in cardiomyocyte proliferation and HSC expansion as well as regulation of cellular metabolism [33]. Besides the role of MEIS1 in healthy organs, maintaining stemness state of cancer stem cells has been also discussed in various cancers. In some cancers including MLL fusion leukemia, it has been reported that MEIS1 is crucial for maintenance of the stem cell molecular profile [34]. Using a knock-in model of mouse leukemia (MLL-AF9), it has been demonstrated that MEIS1 is necessary for maintaining an ESC-like gene signature [34]. In other cancers including neuroblastoma, high level expression of MEIS1 and MEIS2 genes was demonstrated, and

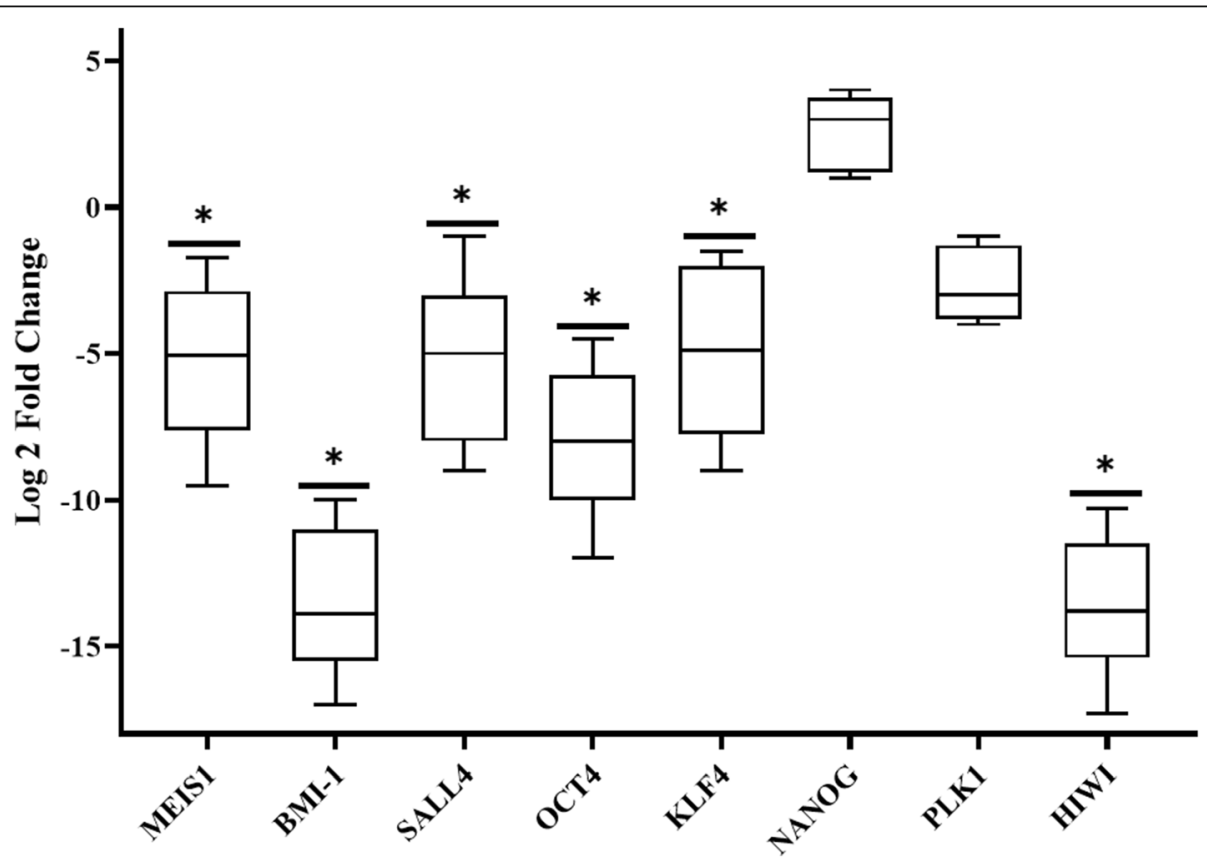

Fig. 2 mRNA expression Levels of MEIS1 and different stem cell markers in MEIS1-silenced cells compared to control are represented as box plots. Each box plot shows median, lower/upper quartile, and highest/lowest observations of log2 fold changes. Asterisks mean statistically significance $(P \leq 0.05)$ 
defective MEIS1 cells showed impaired proliferation leading to cell death [13].

We have recently reported that MEIS1 knockdown in KYSE-30 cells can induce expression of epithelial differentiation markers CDX2, and KRT4, while it can suppress the involved genes in EMT process including TWIST1, EGF [35]. In line with this report, our presented results in this study support the potential oncogenic role for MEIS1 in promoting mesenchymal/ stemness phenotype of ESCC. The role of MEIS1 and its correlation with SOX2 in ESCC has been previously evaluated [15]. MEIS1 expression is decreased in ESCC and inversely related to lymph node metastasis and high tumor stage. Moreover, down regulation of MEIS was correlated with increased expression of SOX2, a master transcription factor of self-renewal [15]. In the present study we evaluated the expression of some CSC markers in ESCC after silencing of MEIS1 and a similar pattern was detected. Various CSCs markers including SALL4, OCT4, BMI-1, HIWI and KLF4 were underexpressed after MEIS1 downregulation. These markers have been proposed as potential self-renewal markers associated with aggressiveness, poor prognosis and cancer recurrence in ESCC [36, 37]. Interestingly, expression of MEIS1 and SALL4 was correlated to each other in ESCCs. Having split the patients based on different pathological states of tumors, we found significant correlation between the genes in primary steps of tumor growth. Indeed, these correlations were observed in tumors without invasion to adventitia layer of the esophagus ( $\mathrm{T} 1$ and $\mathrm{T} 2$ ) presenting early stages of carcinogenesis (stages I and II). This observation may propose a functional involvement of the genes in beginning and promoting ESCC carcinogenesis through advanced stages. Furthermore, a correlation of MEIS1 and SALL4 was found in tumor samples without metastasis, compared to metastasized ESCCs. This correlation indicates a contribution of MEIS1/SALL4 expression in operating cancer aggressiveness in ESCC.

OCT4, KLF4 and SALL4 are a members of a core regulatory network of stem cell maintenance and selfrenewal [38]. The relation between these key stemness factors has been addressed in the literature. The complexity and relation of these stemness factors can be seen in various cancers [39-41]. Also, it has been reported that downregulation of SALL4 resulted in downregulation of both OCT4 and KLF4, ending up in decreasing in reprogramming capacity to induce pluripotent stem cells [42].

In our experience, following MEIS1 down-regulation in ESCC, expression of SALL4 was reduced significantly. Aberrant expression of SALL4 observed in different types of cancers and disruption of multiple cellular tumorigenesis processes suggested a key stemness regulatory effect for SALL4 [43-46]. The possible linkage between SALL4 and other genes discussed in the present study was suggested previously. The role of SALL4, as a major regulator of pluripotency in stem cells, was evaluated in murine-embryonic stem cells and demonstrated that SALL4 downregulation decreased KLF4 expression; the proteins involved in reprogramming somatic cells to pluripotent cells [42].

OCT4 as a critical transcription factor and stem cell marker, is only activated during human embryonic development in pluripotent stem cells, and its expression decreases after stem cell fate decision during embryogenesis $[47,48]$. Our results demonstrated that expression of OCT4 is reduced in MEIS1 silenced ESCC. Yamada et al. demonstrated that MEIS1 is tightly associated with self-renewal signature in hematopoietic and neural stem cells, and can regulate the transcription of the critical stemness genes including OCT4, in such cells [16]. While OCT4 is absent in normal human adult tissue, it has been demonstrated that some benign and malignant human tumors can express OCT4 [49]. OCT4 is a key stemness transcription factor $[21,42,50,51]$ and the importance of OCT4 during carcinogenesis is becoming more evident. Recently, Kim et al. demonstrated that OCT4 expression plays a crucial role in inducing pluripotency in adult neural stem cells, alongside with other markers including SOX2, c-Myc, and KLF4 [17]. OCT4 is regulated by a well-known protein, SALL4. It has been demonstrated that SALL4 can bind to OCT4 promoter and modulate its expression $[52,53]$. Furthermore, expression of BMI-1 was also decreased after MEIS1 knockdown in KYSE-30 cells. It has been demonstrated that SALL4 can upregulates the oncogene BMI-1 expression in human hematopoietic stem cells as well as leukemic cells [54]. BMI-1 is overexpressed in aggressive and recurrent tumors and regulates proliferation, differentiation and senescence of the cells [55]. Increased levels of BMI-1 activated the stemness state in gastric cancer cells, induced by overexpression of SALL4 [56]. Based on the mentioned evidences and our results, the correlation between MEIS1 and BMI-1 may be mediated by SALL4.

KLF4, member of the Kruppel-like factor (KLFs) family of gene regulatory proteins, implicated in the regulation of cell-fate, differentiation, and migration, as well as cancer metastasis $[57,58]$. Reprogramming of somatic cells into pluripotent cells is another major role of KLF4 [19, 20, 59, 60]. According to our results, KLF4 expression was reduced after MEIS1 silencing in ESCC.

Similar to OCT4 and SALL4, the expression of HIWI was reduced after silencing of MEIS1 in ESCC line KYSE-30. While HIWI is a self-renewal marker dealing with regulation of stem cell self-renewal and 
maintenance [22, 61, 62], it's overexpression caused tumorigenesis in multiple malignancies and plays a specific role in CSC-like characteristics of cancer cells [63]. The upregulation of $H I W I$ is significantly associated with a higher clinical stage, and a poorer clinical outcome in esophageal cancer cells. Our study revealed that the level of HIWI mRNA expression was significantly decreased in MESI1 silenced cells in comparison with control cells. This finding has not been widely studied before and the contribution of MEIS1 in HIWI gene regulation should be explored in detail.

Collectively, our results present evidences supporting oncogenic roles for MEIS1 in ESCC through correlation with different stem cell markers.

\section{Conclusions}

The present study demonstrated the important role of MEIS1 in controlling stemness properties of ESCC line KYSE-30. Here we elucidated the correlation between MEIS1 and stemness marker SALL4 in ESCC and revealed significant correlation between the genes in different early pathological features of the disease including non-invaded state, at primary stages of tumor progression. Furthermore, we demonstrated that expression of certain stemness factors including SALL4, OCT4, BMI-1, $H I W I$ and KLF4 genes were significantly decreased after MEIS1 silencing in ESCC line KYSE-30. To the best of our knowledge, this is the first report highlighting the linkage between MEIS1 and the major markers involving in stemness and self-renewal maintenance. These findings suggest a possible therapeutic role for MEIS1 in future cancer therapies based on targeting self-renewal capacities of cancer cells in ESCC.

\section{Abbreviations}

MEIS1: Myeloid ecotropic viral integration site 1; HOX: Homeobox; ESCC: Esophageal Squamous Cell Carcinoma; SALL4: Sal-like protein 4; OCT4: Octamer-binding Transcription Factor 4; BMI-1: B cell-specific Moloney Murine leukemia Virus Integration Site 1; HIWI: Piwi Like RNA-Mediated Gene Silencing 1; PLK1: Polo Like Kinase 1; KLF4: Kruppel Like Factor 1; TALE: 3amino-acid Loop Extension; TWIST1: Twist Family BHLH Transcription Factor 1; EGF: Epidermal Growth Factor; CDX2: Caudal Type Homeobox 2; KRT4: Keratin 4; EMT: Epithelial-Mesenchymal Transition; CSC: Cancer Stemlike Cells; HSC: Hematopoetic Stem Cell; ShRNA: short hairpin RNA; GAPD H: Glyceraldehyde 3-Phosphate Dehydrogenase; CMV: Cytomegalovirus; GFP: Green Fluorescent Protein

\section{Acknowledgments}

The authors acknowledge the colleagues at the Division of Human Genetics, Avicenna Research Institute, MUMS, for preparing ESCC tissue specimens.

\section{Authors' contributions}

SZ drafted the manuscript. ShN and AR performed the experiments. MMF designed the study, analyzed data, edited the manuscript, and had a critical scientific revision on the manuscript. All authors have read and approved the final manuscript.

\section{Funding}

Not applicable.

\section{Availability of data and materials}

All raw data are available in case of request.

\section{Ethics approval and consent to participate}

The study was approved by ethics committee of Mashhad University of Medical Sciences and consent to participate was obtained from all individual participants included in the study.

\section{Consent for publication}

Written informed consent was obtained from the patient for publication of their individual details such as age and gender in this manuscript.

\section{Competing interests}

The authors declare that they have no conflict of interest.

\section{Author details}

${ }^{1}$ Medical Genetics Research Center, Mashhad University of Medical Sciences, Mashhad, Iran. ${ }^{2}$ Department of Biology, Damghan branch, Islamic Azad University, P.O.Box: 3671639998, Cheshmeh-Ali Boulevard, Sa'dei Square, Damghan, Islamic Republic of Iran. ${ }^{3}$ Cellular and Molecular Research center, Sabzevar University of Medical Sciences, Sabzevar, Iran.

Received: 29 April 2020 Accepted: 17 August 2020

Published online: 20 August 2020

\section{References}

1. Enzinger PC, Mayer RJ. Esophageal cancer. N Engl J Med. 2003;349(23):224152.

2. Pennathur A, Gibson MK, Jobe BA, Luketich JD. Oesophageal carcinoma. Lancet. 2013;381(9864):400-12.

3. Bao B, Ahmad A, Azmi AS, Ali S, Sarkar FH. Overview of cancer stem cells (CSCs) and mechanisms of their regulation: implications for cancer therapy. Current protocols in pharmacology. 2013;Chapter 14:Unit 14.25.

4. Aponte PM, Caicedo A. Stemness in Cancer: stem cells, Cancer stem cells, and their microenvironment. Stem Cells Int. 2017;2017:5619472.

5. Crist RC, Roth JJ, Waldman SA, Buchberg AM. A conserved tissue-specific homeodomain-less isoform of MEIS1 is downregulated in colorectal cancer. PLoS One. 2011;6(8):e23665.

6. Grier D, Thompson A, Kwasniewska A, McGonigle G, Halliday H, Lappin T. The pathophysiology of HOX genes and their role in cancer. J Pathol. 2005; 205(2):154-71.

7. Mann RS, Affolter M. Hox proteins meet more partners. Curr Opin Genet Dev. 1998;8(4):423-9.

8. Cai M, Langer EM, Gill JG, Satpathy AT, Albring JC, Wumesh K, et al. Dual actions of Meis1 inhibit erythroid progenitor development and sustain general hematopoietic cell proliferation. Blood. 2012;120(2):335-46.

9. Hisa T, Spence SE, Rachel RA, Fujita M, Nakamura T, Ward JM, et al. Hematopoietic, angiogenic and eye defects in Meis1 mutant animals. EMBO J. 2004;23(2):450-9.

10. Dekel B, Metsuyanim S, Schmidt-Ott KM, Fridman E, Jacob-Hirsch J, Simon A, et al. Multiple imprinted and stemness genes provide a link between normal and tumor progenitor cells of the developing human kidney. Cancer Res. 2006;66(12):6040-9.

11. Thorsteinsdottir U, Kroon E, Jerome L, Blasi F, Sauvageau G. Defining roles for HOX and MEIS1 genes in induction of acute myeloid leukemia. Mol Cell Biol. 2001;21(1):224-34.

12. Qiu Y, Morii E, Tomita Y, Zhang B, Matsumura A, Kitaichi M, et al. Prognostic significance of pre $B$ cell leukemia transcription factor 2 (PBX2) expression in non-small cell lung carcinoma. Cancer Sci. 2009;100(7):1198-209.

13. Geerts D, Schilderink N, Jorritsma G, Versteeg R. The role of the MEIS homeobox genes in neuroblastoma. Cancer Lett. 2003;197(1-2):87-92.

14. Yamashita T, Tazawa S, Yawei Z, Katayama H, Kato Y, Nishiwaki K, et al. Suppression of invasive characteristics by antisense introduction of overexpressed HOX genes in ovarian cancer cells. Int J Oncol. 2006;28(4): 931-8.

15. Rad A, Farshchian M, Forghanifard MM, Matin MM, Bahrami AR, Geerts D, et al. Predicting the molecular role of MEIS1 in esophageal squamous cell carcinoma. Tumor Biol. 2016;37(2):1715-25.

16. Yamada T, Urano-Tashiro Y, Tanaka S, Akiyama H, Tashiro F. Involvement of crosstalk between Oct4 and Meis1a in neural cell fate decision. PLoS One. 2013;8(2):e56997. 
17. Kim JB, Sebastiano V, Wu G, Araúzo-Bravo MJ, Sasse P, Gentile L, et al. Oct4induced pluripotency in adult neural stem cells. Cell. 2009;136(3):411-9.

18. Zaehres H, Schöler HR. Induction of pluripotency: from mouse to human. Cell. 2007;131(5):834-5.

19. Kim D, Kim C-H, Moon J-I, Chung Y-G, Chang M-Y, Han B-S, et al. Generation of human induced pluripotent stem cells by direct delivery of reprogramming proteins. Cell Stem Cell. 2009;4(6):472.

20. Takahashi K, Tanabe K, Ohnuki M, Narita M, Ichisaka T. Tomoda K, et al. Induction of pluripotent stem cells from adult human fibroblasts by defined factors cell. 2007;131(5):861-72.

21. Tanimura N, Saito M, Ebisuya M, Nishida E, Ishikawa F. Stemness-related factor Sall4 interacts with transcription factors Oct-3/4 and Sox2 and occupies Oct-sox elements in mouse embryonic stem cells. J Biol Chem. 2013;288(7):5027-38.

22. Grochola L, Greither T, Taubert H, Möller P, Knippschild U, Udelnow A, et al. The stem cell-associated Hiwi gene in human adenocarcinoma of the pancreas: expression and risk of tumour-related death. Br J Cancer. 2008; 99(7):1083.

23. Stewart R, Stojkovic M, Lako M. Mechanisms of self-renewal in human embryonic stem cells. Eur J Cancer. 2006;42(9):1257-72.

24. Boiani M, Schöler HR. Developmental cell biology: regulatory networks in embryo-derived pluripotent stem cells. Nat Rev Mol Cell Biol. 2005;6(11):872.

25. Parizadeh SM, Jafarzadeh-Esfehani R, Hassanian SM, Parizadeh SMR, Vojdani S, Ghandehari M, et al. Targeting cancer stem cells as therapeutic approach in the treatment of colorectal cancer. Int J Biochem Cell Biol. 2019;110:75-83.

26. Forghanifard MM, Khales SA, Javdani-Mallak A, Rad A, Farshchian M, Abbaszadegan MR. Stemness state regulators SALL4 and SOX2 are involved in progression and invasiveness of esophageal squamous cell carcinoma. Med Oncol. 2014:31(4):922.

27. Root DE, Hacohen N, Hahn WC, Lander ES, Sabatini DM. Genome-scale lossof-function screening with a lentiviral RNAi library. Nat Methods. 2006:3(9):715.

28. Barde I, Salmon P, Trono D. Production and titration of lentiviral vectors. Current protocols in neuroscience. 2010;53(1):4.21. 1-4.. 3.

29. Rad A, Dizghandi SE, Abbaszadegan MR, Taghechian N, Najafi M, Forghanifard MM. SOX1 is correlated to stemness state regulator SALL4 through progression and invasiveness of esophageal squamous cell carcinoma. Gene. 2016;594(2):171-5.

30. Thrift AP, Whiteman DC. The incidence of esophageal adenocarcinoma continues to rise: analysis of period and birth cohort effects on recent trends. Annals of oncology : official journal of the European Society for Medical Oncology. 2012;23(12):3155-62.

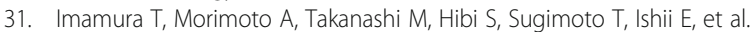
Frequent co-expression of HoxA9 and Meis1 genes in infant acute Iymphoblastic leukaemia with MLL rearrangement. Br J Haematol. 2002; 119(1):119-21.

32. Azcoitia $V$, Aracil M, Martinez AC, Torres M. The homeodomain protein Meis1 is essential for definitive hematopoiesis and vascular patterning in the mouse embryo. Dev Biol. 2005;280(2):307-20.

33. Aksoz M, Turan RD, Albayrak E, Kocabas F. Emerging roles of Meis1 in cardiac regeneration, stem cells and Cancer. Curr Drug Targets. 2018;19(2): 181-90.

34. Kumar AR, Sarver AL, Wu B, Kersey JH. Meis1 maintains stemness signature in MLL-AF9 leukemia. 2010;115(17):3642-3.

35. Mahmoudian RA, Bahadori B, Rad A, Abbaszadegan MR, Forghanifard MM. MEIS1 knockdown may promote differentiation of esophageal squamous carcinoma cell line KYSE-30. Molecular genetics \& genomic medicine. 2019; 7(7):e00746.

36. Ben-Porath I, Thomson MW, Carey VJ, Ge R, Bell GW, Regev A, et al. An embryonic stem cell-like gene expression signature in poorly differentiated aggressive human tumors. Nat Genet. 2008;40(5):499.

37. Luo W, Li S, Peng B, Ye Y, Deng X, Yao K. Embryonic stem cells markers SOX2, OCT4 and Nanog expression and their correlations with epithelialmesenchymal transition in nasopharyngeal carcinoma. PLoS One. 2013;8(2): e56324.

38. Zhao W, Li Y, Zhang X. Stemness-related markers in Cancer. Cancer translational medicine. 2017;3(3):87-95.

39. Rodriguez E, Chen L, Ao M-H, Geddes S, Gabrielson E, Askin F, et al. Expression of transcript factors SALL4 and OCT4 in a subset of non-small cell lung carcinomas (NSCLC). Translational Respiratory Medicine. 2014;2(1):10.
40. Park JT, Chen X, Trope CG, Davidson B, Shih I-M, Wang T-L. Notch3 overexpression is related to the recurrence of ovarian cancer and confers resistance to carboplatin. Am J Pathol. 2010;177(3):1087-94.

41. Müller M, Hermann PC, Liebau S, Weidgang C, Seufferlein T, Kleger A, et al. The role of pluripotency factors to drive stemness in gastrointestinal cancer. Stem Cell Res. 2016;16(2):349-57.

42. Yang J, Chai L, Fowles TC, Alipio Z, Xu D, Fink LM, et al. Genome-wide analysis reveals Sall4 to be a major regulator of pluripotency in murineembryonic stem cells. Proc Natl Acad Sci. 2008;105(50):19756-61.

43. Tatetsu H, Kong NR, Chong G, Amabile G, Tenen DG, Chai L. SALL4, the missing link between stem cells, development and cancer. Gene. 2016; 584(2):111-9.

44. Xiong J. SALL4: engine of cell stemness. Current gene therapy. 2014;14(5): 400-11.

45. Zhang $X$, Yuan $X$, Zhu W, Qian H, Xu W. SALL4: an emerging cancer biomarker and target. Cancer Lett. 2015;357(1):55-62.

46. Wang F, Zhao W, Kong N, Cui W, Chai L. The next new target in leukemia: the embryonic stem cell gene SALL4. Molecular \& cellular oncology. 2014; 1(4):e969169.

47. Lee J, Kim HK, Rho J-Y, Han Y-M, Kim J. The human OCT-4 isoforms differ in their ability to confer self-renewal. J Biol Chem. 2006;281(44):33554-65.

48. Pesce $M$, Schöler HR. Oct-4: gatekeeper in the beginnings of mammalian development. Stem Cells. 2001;19(4):271-8.

49. Tai M-H, Chang C-C, Olson LK, Trosko JE. Oct4 expression in adult human stem cells: evidence in support of the stem cell theory of carcinogenesis. Carcinogenesis. 2005;26(2):495-502.

50. Yang J, Gao C, Chai L, Ma Y. A novel SALL4/OCT4 transcriptional feedback network for pluripotency of embryonic stem cells. PLoS One. 2010;5(5): e10766.

51. Wu Q, Chen X, Zhang J, Loh Y-H, Low T-Y, Zhang W, et al. Sall4 interacts with Nanog and co-occupies Nanog genomic sites in embryonic stem cells. J Biol Chem. 2006;281(34):24090-4.

52. Lee KC, Wong WK, Feng B. Decoding the Pluripotency network: the emergence of new transcription factors. Biomedicines. 2013;1(1):49-78.

53. Zhang J, Tam W-L, Tong GQ, Wu Q, Chan H-Y, Soh B-S, et al. Sall4 modulates embryonic stem cell pluripotency and early embryonic development by the transcriptional regulation of Pou5f1. Nat Cell Biol. 2006; 8(10):1114-23.

54. Yang J, Chai L, Liu F, Fink LM, Lin P, Silberstein LE, et al. Bmi-1 is a target gene for SALL4 in hematopoietic and leukemic cells. Proc Natl Acad Sci. 2007:104(25):10494-9.

55. Leung C, Lingbeek M, Shakhova O, Liu J, Tanger E, Saremaslani P, et al. Bmi is essential for cerebellar development and is overexpressed in human medulloblastomas. Nature. 2004;428(6980):337.

56. Zhang L, Xu Z, Xu X, Zhang B, Wu H, Wang M, et al. SALL4, a novel marker for human gastric carcinogenesis and metastasis. Oncogene. 2014;33(48): 5491.

57. Rowland BD, Bernards R, Peeper DS. The KLF4 tumour suppressor is a transcriptional repressor of p53 that acts as a context-dependent oncogene. Nat Cell Biol. 2005;7(11):1074.

58. McConnell BB, Ghaleb AM, Nandan MO, Yang WW. The diverse functions of Kruppel-like factors 4 and 5 in epithelial biology and pathobiology (vol 29, pg 549, 2007). Bioessays. 2007;29(9):946-

59. Takahashi K. Yamanaka S. Induction of pluripotent stem cells from mouse embryonic and adult fibroblast cultures by defined factors cell. 2006;126(4): 663-76.

60. Yamanaka S. Strategies and new developments in the generation of patient-specific pluripotent stem cells. Cell Stem Cell. 2007;1(1):39-49.

61. Seto AG, Kingston RE, Lau NC. The coming of age for Piwi proteins. Mol Cell. 2007;26(5):603-9.

62. He W, Wang Z, Wang Q, Fan Q, Shou C, Wang J, et al. Expression of HIWI in human esophageal squamous cell carcinoma is significantly associated with poorer prognosis. BMC Cancer. 2009;9(1):426.

63. Wang $Y$, Jiang $Y$, Bian C, Dong Y, Ma C, Hu X, et al. Overexpression of Hiwi inhibits the cell growth of chronic myeloid leukemia K562 cells and enhances their chemosensitivity to daunomycin. Cell Biochem Biophys. 2015;73(1):129-35

\section{Publisher's Note}

Springer Nature remains neutral with regard to jurisdictional claims in published maps and institutional affiliations. 